\title{
MIRCEA ELIADE: UN CAMINO FENOMENOLÓGICO PARA COMPRENDER LA EXPERIENCIA RELIGIOSA EN UNA ÉPOCA SECULAR ${ }^{*}$
}

\author{
MIRCEA ELIADE: A PHENOMENOLOGICAL PATH TO UNDERSTAND \\ THE RELIGIOUS EXPERIENCE IN A SECULAR AGE
}

\author{
Prof. Carolina Lagos Oróstica ${ }^{2}$ \\ Universidad Católica de la Santísima Concepción, Chile
}

\begin{abstract}
Resumen: Este artículo propone una aproximación a la comprensión del homo religiosus desde la perspectiva fenomenológica del rumano Mircea Eliade, quien piensa que todas las épocas y culturas han desarrollado gran parte de su existencia completamente mediatizadas por la relación del hombre con lo trascendente. El propósito es ofrecer una reflexión sobre el fenómeno religioso desde su universalidad antropológica; y, en este sentido, comprender la experiencia de la religiosidad en el actual paradigma social. El interés por abordar la dimensión de comunicación humana con lo sagrado, aquí se expone desde el entendido que la religión es el contenido más radical del existir humano, también en nuestra época donde el ethos social es marcado por la secularidad.
\end{abstract}

Descriptores: Eliade $\cdot$ Religión $\cdot$ Sagrado $\cdot$ Secular.

Abstract: This article proposes an appoach to the understanding of homo religiosus starting from the phenomenological perspective of the Romain Mircea Eliade, who thinks that all ages and cultures have developed their existence fully mediated by the relationship of man with the trascendent. The purpose is to offer a reflection on the religiosus ages phenomenon from its anthropological universality, and, in this sense, to understand, the experience of religiosity in the current social paradigm. The interest to approach the dimension of human comunication with the sacred is exposed here from the understading that religion is the most radical content of human existence also in our age marked by secularity.

Keywords: Eliade $\cdot$ Religion $\cdot$ Sacred $\cdot$ Secular.

"Al volver a tener conciencia de su propio simbolismo anthropocósmico -que no es sino una variante del simbolismo arcaico-, el hombre moderno obtendrá una nueva dimensión existencial totalmente ignorada por el existencialismo

\footnotetext{
${ }^{1^{*}}$ Artículo es una versión relaborada a partir de la ponencia La dialéctica de lo sagrado y lo profano: Antecedentes para una comprensión antropocultural en una época secular, expuesta en el Primer Congreso Internacional del Centro de Estudios de la Religión UC "Las Religiones y Ámbito Público", realizado en la Pontificia Universidad Católica de Chile, Santiago, 11-13 de octubre de 2016.

${ }^{2}$ Magíster en Filosofía Moral. Universidad de Concepción, Chile. Candidata a Doctora en Filosofía, Universidad Pontificia de Salamanca, España. E-mail: clagos@ucsc.cl
} 
e historicismo actuales: un modo de ser auténtico y superior que le defienda del nihilismo y del relativismo historicista sin sustraerse por ello de su historia”. Eliade (1983), p. 39.

\section{PRESENTACIÓN}

Las nociones acerca de la religión, habitualmente se sitúan sobre el entendido que se trata de una vivencia humana vinculada a un ser superior poseedor de un carácter distinto al humano. Aceptado como un fenómeno cultural que representa lo trascendente, el contenido religioso, generalmente, es asumido como la manifestación de Dios, dioses y fuerzas sagradas que vienen al mundo desde una dimensión a él opuesta, pero que influyen misteriosamente en el devenir cotidiano.

En las actuales circunstancias sociales de ocultamiento de las prácticas religiosas -al menos en el espacio público de la cultura secular occidental-, surge la necesidad de exponer aquellas categorías centrales que orientan las descripciones, definiciones y explicaciones de la religión, en tanto fenómeno universal e irreductible a otros fenómenos socioculturales. En este sentido, parte de la importancia de la filosofía de la religión, radica en que posee la capacidad de explicar el manifiesto carácter metafísico de su objeto de estudio que se expresa desde múltiples y variadas formas, logrando desarrollar una reflexión sobre la racionalidad del hecho religioso, presentado por la fenomenología (Lucas, 1999, p. 41).

Por su parte, el análisis fenomenológico, ${ }^{3}$ expresa el interés por comprender e interpretar la religión en su totalidad (Alessi, 2004, p. 194), en función de sí misma (Pals, 2008, p. 325) y a partir de su modalidad propia, es decir, a escala religiosa (Eliade, 2011. p. 55). La fenomenología de la religión reconoce la especificidad de la religión, observándola como un contenido particular que surge de la peculiar intencionalidad del ser humano como ser religioso. Frente a dicha intencionalidad humana, Mircea Eliade tiene muy en cuenta la participación de los elementos materiales componentes del fenómeno, proponiendo un análisis que debe incluir el estudio comparado de las religiones, la fenomenología de las religiones y la morfología religiosa. Según Mircea, la insuficiencia de una sola explicación sobre el significado de la religión, instala la necesidad de interpretar las implicaciones culturales que se relacionan con el desarrollo de la «historia» del fenómeno religioso (Eliade, 2000. p. 22). De acuerdo a esto, la historia de las religiones y fenomenolo-

\footnotetext{
${ }^{3}$ La expresión «fenomenología de la religión» fue empleada por primera vez en 1887 en el Manual de la historia de la religión de Pierre Daniel Chantépie de la Saussaye. Posteriormente, en 1915 Gerardus van der Leeuw plantea en su Introducción a la fenomenología de la religión, un camino que culminará en su Fenomenología de la religión. Este título ha sido adoptado hasta la actualidad para nombrar la metodología del estudio religioso, utilizada por autores como Mircea Eliade. Cf. Shaeffler. R. (2003). Filosofia de la Religión, Salamanca, Sígueme, 93.94.
} 
gía de la religión, son dos aspectos complementarios de una ciencia integral de la religión. La fenomenología de la religión en la exposición del rumano, por razones metodológicas, incluye las formas elementales de las culturas que siempre penetran en la vida religiosa. En este sentido, su enfoque procura aportar en la comprensión religiosa de la cultura, ${ }^{4}$ porque su método es el resultado de un análisis sistemático (Allen, 1985, p. 53) de los elementos simbólicos-rituales que observa en distintas religiones. En definitiva, el punto de vista eliadeano ofrece una base de orientación rigurosamente elaborada, sostenida además, en la interpretación hermenéutica de los datos religiosos.

También es valorable el aporte a la antropología de la religión surgida desde la perspectiva eliadeana, pues al no cerrar sus examinaciones al interior de los ámbitos lingüísticos, fisiológicos, psicológicos o sociológicos, ${ }^{5}$ conforma una particular vía de ingreso a la esencialidad de la religión: la experiencia de lo sagrado (Eliade, 2011, p. 55). Cabe señalar que para el autor rumano, es imprescindible constatar que la experiencia religiosa posee su categoría central e indispensable en la vivencia de captación de lo trascedente; por tanto, la profusa exposición y descripción de mitos, símbolos y ritos que su obra muestra, sirve para entender la dialéctica de lo sagrado y lo profano como condición universalmente articuladora del carácter del hombre en el mundo. La experiencia religiosa, tal como Eliade la asume, puede entenderse como la experiencia integral de la especie humana, dado que contiene todas las otras formas de la experiencia de la trascendencia (Martín Velasco, 2002, p. 159).

Según lo anterior y yendo más allá de las demarcaciones que destacan la función reguladora de la religión en las estructuras sociales, ${ }^{6}$ es prioridad apreciar que la religión es el contenido que descubre las más íntimas aspiraciones y motivaciones del ser humano, manifestadas en sentimientos de asombro, admiración y atracción frente a la irrupción de lo sagrado al interior del mundo ordinario. Eliade

\footnotetext{
${ }^{4}$ Véase, Petazzoni R. (1965). 'El ser supremo: Estructura fenomenológica y desarrollo histórico'. En: Mircea Eliade y Joseph Kitagawa (comps.), Metodología de la Historia de las Religiones, Barcelona, Paidós, (pp. 85.94).

${ }^{5}$ Estudios como los de Marx o Freud, poseen limitaciones al considerar que la religión es fruto de una conciencia pre-científica que carece de legitimidad frente al desarrollo de la filosofía y la ciencia. Karl Marx entiende que la religión es un opio para el pueblo que resuelve vicariamente sus esperanzas no cumplidas. Sigmund Freud, ve en la religión no más que un medio para nutrir la desolación humana ante la angustia de vivir en una sociedad que lesiona y traumatiza. Cf., Shaeffler. R. (2003), Filosofía de la religión, Salamanca, Sígueme, 20.23. Por su parte, Eliade coincide con van der Leeuw respecto a que el fenómeno religioso no puede estudiarse desde ningún reduccionismo. Del mismo modo, se opone al intelectualismo y las simples interpretaciones lingüísticas, antropológicas, sociológicas y psicológicas. Cf. Allen, D. (1985). Mircea Eliade y el fenómeno religioso, Ediciones Cristiandad, Madrid, 58.59.

${ }^{6}$ Véase de Juan Marín Velasco, Introducción a la Fenomenología de la Religión (Ediciones Cristiandad, 1978). Aquí se explica la limitación de los análisis reduccionistas, a través de un análisis sobre la fenomenología aplicada al estudio de lo Sagrado.
} 
afirma que la religión ha establecido una modalidad intelectual única, capaz de develar el más profundo compromiso existencial del ser humano y su historia; configurado con ello, las expresiones de su modo de ser religioso. El escrito que aquí se desarrolla, atiende en primer término, al lugar que posee la experiencia de lo sagrado en la definición de Mircea Eliade. Como segundo aspecto, se mira la experiencia de lo sagrado en el presente de la cultura occidental, autodefinida como sociedad secular.

\section{LA RELIGIÓN EN EL ANÁLISIS DE ELIADE}

Si bien las observaciones históricas descriptivas de Mircea Eliade se refieren principalmente a las comunidades donde el mito posee vida, ${ }^{7}$ en el sentido que es un modelo para la conducta del hombre, no deja de lado que la religión responde a la estructura de la inteligencia humana en términos universales. Según ello, el autor entiende que el ser humano nunca puede hallarse del todo desacralizado, pues el ejercicio de la vida no puede efectuarse únicamente en conexión con el mundo histórico y natural (Eliade, 2000, p. 11), sino esencialmente a partir del encuentro con lo trascendente. En este sentido, el surgimiento del fenómeno religioso, no es el aparecer de una realidad limitada al interior de la dimensión espacio-temporal como podría pensarse; en ella existen dos aspectos fundamentales de universalidad y transversalidad que dan cuenta de su configuración como una experiencia cognoscitiva transversal en términos antropológicos, desde la cual el hombre ha diseñado su camino de orientación y búsqueda existencial a lo largo de toda la historia. Por esta razón, para Eliade la historia de la humanidad es la historia de su religiosidad. La secularización dentro de ella, no sería otro elemento que el planteamiento de una decisión consciente que ha provocado el vaciamiento progresivo de los antiguos dogmas, rituales e instituciones religiosas; en consecuencia, una vida ejercida en distancia de la connatural religiosidad, sin conseguir de modo definitivo su erradicación. Porque la continuidad del Universo imaginario del hombre y su modo existencial (Eliade, 2000, p. 11), se revela en otras experiencias vitales de comunicación; por ejemplo, en las ofrendas a una naturaleza de fuerza superior, misteriosa y envolvente. Mircea Eliade dirá que la especificidad del fenómeno religioso, se debe especialmente a la condición antropológica universal de la unidad religiosa de la inteligencia humana. Lo que significa que la aparición del conocimiento, en tanto conocimiento religioso, se ha provocado gracias al acceso de la inteligencia a "los conceptos de ser, sentido y verdad" (Eliade, 2000, p. 7).

\footnotetext{
${ }^{7}$ Véase, Eliade, M. (1996). Mito y Realidad, Colombia, Labor.
} 
Quedando demostrado que la religión no se refiere únicamente a las creencias tradicionales, sino a una completa vivencia metafísica de captación y conocimiento del ser. Este acontecimiento único que ha permitido la generación de una ontología explicativa, Eliade lo identifica como el momento primordial en la preparación y posterior desarrollo del pensamiento sistemático de la inteligencia humana: "La experiencia de lo sagrado, al revelar el ser, el sentido y la verdad en mundo desconocido, caótico y temeroso, preparó el camino para el pensamiento sistemático" (Eliade, 2000. p, 8). La religión se origina a partir de una manifestación de la consciencia humana en su capacidad de internalizar comprensivamente los aspectos concernientes a la potencia y eficacia (Eliade, 2016. p, 15.16) trascendente. En tal sentido, no podría ocultarse el carácter intelectual de la religión que ha facultado al ser humano en su potencialidad de conocimiento válido y eficaz del mundo, así como en la pertenencia de su propia forma de autotrascedencia en él. En consecuencia, la experiencia de lo sagrado es "el fenómeno antropológico por excelencia" (Duch, 2001. p, 100) que pone al descubierto la intencionalidad de la inteligencia (Lucas, 1994. p, 117.118) en su milenaria búsqueda de respuestas a cuestiones que plantea la vida propiamente humana. De manera efectiva, la experiencia de lo sagrado ha entregado al ser humano la posibilidad de identificar el orden significativo del mundo y descubrir lo real en él, consiguiendo llevar a cabo la tarea de configurar un espacio habitable compuesto de referencias procedentes de verdades sagradas. De tal modo, afirma Eliade, la religión se demuestra como un proceso de la inteligencia que diferencia entre lo que se revela como poderoso y significativo, frente a lo caótico y carente de sentido.

Todas las expresiones religiosas ${ }^{8}$ responden a una sola constitución humana del homo religiosus: la necesidad de enfrentar las ambivalencias de la existencia; la nada con el ser, la muerte con la vida, el caos con el orden y la limitación con la salvación. En suma, la religión corresponde a aquella realidad universal, original y perdurable, desde la cual el discernimiento humano ha conocido su lugar en el Universo (Eliade, 1983, p. 37). Al concebir que la estructura de inteligencia es esencialmente religiosa, Eliade no solo destaca el hecho que gran parte de las cosas existentes en algún momento de la histo-

\footnotetext{
${ }^{8}$ Es favorable considerar todas las expresiones de la experiencia religiosa, incluso aquellas sobre las que se ha discutido su condición religiosa, como es el caso del budismo, a veces indicado como "religión atea", porque no tiene la representación de un ser absoluto y solo la relación del hombre con el más allá, frente a las tradiciones judío-cristiana e islámica que sí definen una realidad superior correspondiente a Dios. No puede obviarse que en otras formas religiosas se ha asumido al Misterio como un prius reconocido por los hombres al momento de introducirse en el mundo de lo sagrado. Cf., Fraijó, M. (2005). Filosofía de la religión, Madrid, Trotta, 75.
} 
ria hayan sido intelegidas como revelaciones hierofánicas, igualmente enfatiza que el fenómeno religioso nace en un acto subjetivo del hombre afectado por lo divino. Según esto, la religión en su conjunto, es una actividad intencionada y dirigida hacia algo transpersonal que constituye la meta y el fin de la experiencia sagrada. Esta intencionalidad exige al ser humano establecer una definición sobre hacia qué tender y cómo realizar esa tendencia; en otras palabras, definir cómo ejercitar el compromiso permanente y total con lo sagrado desde su intelectualidad, espiritualidad y corporeidad puestas en el mundo.

Entendida como condición sustancial del hombre que se exhibe en una experiencia indagadora, vital y afectante de todas sus facultades y planos de acción, la religión es la vía universal y trascendental por la que transita aquello que conocemos como la búsqueda de la trascendencia (Martín Velasco, 2002, p. 159). Ante esto, la fenomenología eliadeana, acude al discernimiento hermenéutico interesado en la decodificación de las experiencias religiosas en su plano de referencia propio, así el estudio consigue evidenciar que, entre las diferentes expresiones simbólicas-religiosas, existe una solidaridad estructural (Allen, 1985, p. 193), mostrando que en todas las formas de vida religiosa se presenta la indivisible unidad de la inteligencia; por lo tanto, el fenómeno es uno y siempre el mismo, polisémico en sus formas y conducciones.

Por otra parte, el problematismo ontológico de la religión, referido a lo real y lo existente, deduce una obligación para el comportamiento humano, una incondicionalidad hacia valores absolutos, ejemplares y significativos que confiere a las culturas su forma. En este sentido, los valores religiosos al interior de una sociedad secularizada igualmente tienden a permanecer, precisamente porque la religión no es un contenido "superable", como se pudo haber pensado en la época del espíritu positivo y las ciencias, ${ }^{9}$ sino que es una cualidad estructuradora de la conciencia. Aspecto que en términos antropológicos, lleva a Eliade a sostener que "ser -o más bien devenir- un ser humano significa ser «religioso»" (Eliade, 2000. p, 8). Se puede sostener que la religión no es parte de un periodo o fase dentro de la evolución de la humanidad, sino un elemento conformante de la condittio humana (Luckman, 2008. p, 5) que no parte de una conceptualización lógica sobre el mundo, pero que ha sido el significante

\footnotetext{
${ }^{9}$ El estudio de las religiones comparadas se inicia en el siglo XIX, periodo de la más alta propaganda materialista y positivista. En 1852 Comte publica su Catecismo Positivista y Max Müller publica Mitología Comparada en 1865; en 1871 Burnett Tylor propone en su Cultura primitiva una teoría evolucionista sobre las religiones, señalando que en una primera etapa existió un animismo que confería poder a la naturaleza. Para Eliade, estas ideas representan el interés de una época deseosa de descubrir las estructuras de la Materia, los orígenes de la Vida y de la Mente y no serían más que respuestas al anhelo de traspasar el tiempo y el espacio para alcanzar los límites y comienzos del universo, pero no explican qué es la religión o cómo se origina. Cf., Eliade, M. (2000), La búsqueda, Barcelona, Kairós, 63.64.
} 
más radical para la fundación del mundo y el desarrollo de una vida humana envuelta por el misterio. ${ }^{10}$

La experiencia sagrada que vive el ser humano es atribuida al descubrimiento que él hace del movimiento dialéctico entre lo sagrado y lo profano (Eliade, 2011, p. 64), a través de esta vivencia el homo religiosus logra el ingreso al misterio de la totalidad y declara una postura frente a ese misterio. Las sociedades que poseen una cosmovisión religiosa de la realidad siempre tienen espacio para el misterio, viven bajo el influjo de la dialéctica sagrado-profano, situación que impone un permanente enfrentamiento a las condiciones propias de la vida humana. Muy distinto es en las sociedades cuya visión de la realidad es puramente histórica-material, aquí la realización del hombre depende de su sola fuerza. Entonces en una vida moderna creada de espaldas a la metafísica, ¿a qué se debe la nostalgia por los orígenes?, ¿en qué radica el deseo permanente por resguardar acontecimientos donde se descubren situaciones santas que muestran la distancia de lo sagrado, frente al espacio homogéneo? La explicación de Mircea es que, en la experiencia de la vida secular, permanece la intervención de una serie de valores simbólicos que recuerdan al ser humano la coexistencia de planos cualitativamente diferentes, sagrados y profanos; a través de los cuales puede dotar existencialmente su vida y reintegrar lo trascendente en ella: suprimir temporalmente la concepción lineal del tiempo y la historia. Para Eliade: “incluso la existencia más desacralizada sigue conservando vestigios de una valoración religiosa del mundo (...). Subsisten lugares privilegiados, cualitativamente diferentes de otros: el paisaje natal, el paraje de los primeros amores, una calle o un rincón de la primera ciudad extranjera visitada en la juventud. Todos estos lugares conservan, incluso para el hombre más declaradamente no religioso, una cualidad excepcional, «única»: son los «lugares santos» de su universo privado" (Eliade, 2015, p. 23).

¿Podría pensarse en una necesidad iniciática en el hombre moderno? Al parecer, indica Eliade, la carencia del hombre moderno tiene su causa en la falta de acceso directo a los símbolos que provocan modificaciones al estado personal. La cultura racionalista no posee medios para resolver la necesidad de mutación ontológica (Eliade, 2000, p. 152) simbólica; por lo tanto, limita su condición existencial al devenir lineal del tiempo, razón por la cual las personas no poseen los medios efectivos para el ejercicio de reconocerse como seres limitados y finitos.

\footnotetext{
${ }^{10}$ Etimológicamente la palabra misterio proviene del griego muo: cerrar los ojos o callar, un significado que alude al obligatorio silencio que provoca una presencia inesperada. El solo análisis de la palabra misterio equivale a un ingreso hacia el sentido de la Divinidad. La filosofía moderna y contemporánea quisieron prescindir de la zona del misterio, haciendo del racionalismo la vía para una explicación total de la realidad. No obstante, ante el misterio brotan las inquietudes humanas que notifican una necesidad en la hondura del hombre. Cf., Farré, L. (1969), Filosofía de la religión, Buenos Aires, Losada, 276.278.
} 
El juzgar de Mircea, es que la sociedad contemporánea debe reencontrarse con las primeras reflexiones acerca del fundamento del mundo, concediéndose la oportunidad cultural de recobrar un punto de partida (Eliade, 2001, p. 200) o un "punto fijo" (Eliade, 2015, p. 21) original para el desarrollo de su propio modo de estar implantado en el mundo. Es decir, redescubrir los fundamentos religiosos de la ontología declarada originalmente en ideogramas, mitos cósmicos y genealógicos que fueron elaborados por las sociedades tradicionales como medios de autodefensa frente a la nada (Eliade, 2011, pp. 103.104). Probablemente esto incida en la valoración que hoy se tiene de la religión como sistema cognitivo que faculta el desarrollo de comportamientos resolutivos, practicados por el hombre ante la presencia de un absoluto-superior-sagrado que le interpela dialógicamente, al tiempo que le entrega el camino de salvación a su inconsistencia ontológica.

\section{LA EXPERIENCIA DE LO SAGRADO EN EL PRESENTE SECULAR}

Comprender la situación de distanciamiento del hombre con su connatural religiosidad, implica prestar atención la situación de pérdida de los referentes de orden metafísico como pilares para el desarrollo social de Occidente, entre otras razones, debido al lugar de privilegio que ha adquirido el ideal materialista y la racionalización cosificadora de toda entidad cognoscible. El soterramiento de la naturaleza religiosa del hombre, en parte deriva del pensamiento moderno y su proyecto de cultura convencida de la feliz unión entre industrialización y secularización (Luckmann,1973). Situación que a la larga, significó un decaimiento en la manifestación pública de las formas religiosas. De tal manera, la actividad institucionalizadora de la religión sufrió un retraimiento hacia el espacio privado, sus formas significativas hoy son reemplazadas por las estructuras políticas, económicas, científicas y tecnológicas como sistemas de saber encargados de establecer los valores normativos para la comunidad. De este modo, el hombre de nuestros tiempos, percibe que la religión es un dispositivo destinado a unas vivencias únicamente privadas que nada pueden aportar al cultivo social.

La modernidad introduce la idea que la ciencia y la técnica son agentes que movilizan el entendimiento humano hacia logros autónomos del ejercicio racional; no obstante, la consecuencia es una sociedad huérfana y desencantada de las cosmovisiones sagradas. La desorientación que experimenta la época presente, se plasma en sus acciones sociales respondientes a una racionalización de la vida en amplios sentidos. Existe una fracturación de la tradición en la cultura a causa de la pérdida del sentido vital de la existencia y, por ello, hoy es tan necesario dejar al homo religiosus expresarse, dar importancia a la sabiduría metafísica de los contenidos religiosos, cuyo valor no es visto en los espacios de actuación donde prima el racionalismo técnico que impone otras formas de culto (Habermas, 1986, p. 54). 
Hablar actualmente del hecho religioso en los ámbitos relacionados al desarrollo social, conlleva explicar que la religión ha retrocedido no por falta de validez en su estructura y morfología, sino por el rechazo programado ideológicamente respecto a su participación en términos institucionales. ${ }^{11}$

De acuerdo al postulado de Eliade, como se ha señalado, la religión centra su origen la conciencia humana. Por lo tanto, la instauración del orden metafísico y el mismo carácter simbólico de la realidad, permanecen inextinguibles para el ser humano, aunque los contenidos religiosos sean reemplazados por otras instituciones legitimadas. Esto quiere decir que la secularización se encarga del trasvase de contenidos y valores religiosos, hacia las instituciones públicamente reconocidas como fundamento imprescindible del hacer sociocultural; ello demuestra que la erradicación de la religiosidad en el espacio civil, de ningún modo aniquila la religiosidad del hombre.

Si bien es cierto, el ejercicio de la institucionalidad política hoy no solicita de la doctrina religiosa para la dirección de acciones, medios y fines, es imposible que la liberalización social respecto a los valores religiosos, pueda asolar la religación humana hacia lo trascendente. Una señal lamentable del proceso de desacralización, sostiene Eliade, es que en ocasiones el hombre acude a formas híbridas o sectas de pseudo ocultismo (Eliade, 2015, p. 150), cuestión que reviste el grave peligro de prácticas antirreligiosas camufladas como comportamientos religiosos; “ideologías donde se pueden entrever las huellas de la «nostalgia del paraíso» (Eliade, 2015, p.151).

El distanciamiento de las regulaciones procedentes del marco de la tradición, desde la modernidad hasta las transformaciones sociales de los siglos XVIII y XIX, ha enlazado muy bien con el proyecto de la sociedad actual donde las especializaciones funcionales de las instituciones debilitan el reconocimiento de la dialéctica de lo sagrado y lo profano. La crítica racionalista hacia las sociedades tradicionales, es que estas no podían darse cuenta de la libertad restringida por la religión; ante ello, el llamamiento tecnocrático es que el ser humano promueva los elementos que facilitan la emancipación frente a los valores religiosos. Desde aquí, la creencia ha sido que los conocimientos científicos, políticos, económicos y tecnológicos entregan al mundo físico su total independencia; circunstancias en las que no es extraño el éxito de la globalización política y económica que, en gran medida, depende de la liberalización de las costumbres que antes fueron orientadas para alcanzar la vida eterna. Una vez definido un modo de pensamiento sostenido en los principios de racionalidad y autonomía, el discurso sobre la posibilidad de una

\footnotetext{
1 Véase, Touraine, A. (2008). 'Las relaciones entre religión y política en las sociedades contemporáneas'. En: Bericat Alastuey, E. (coord.), El fenómeno religioso. Presencia de la religión y de la religiosidad en las sociedades avanzadas, Sevilla: Centro de Estudios Andaluces, (pp.97.103).
} 
civilización superior se vuelve fascinante y el paradigma que entiende la madurez de la humanidad gracias al retiro de la fe y el dogma, se materializa posibilitando la realización de una ciencia productora y distribuidora de las visiones del mundo.

En este cuadro, la secularización como elemento fundamental para comprender la sociedad occidental desde la modernidad a la fecha, de acuerdo a Charles Taylor (2007), puede identificarse desde tres sentidos: Primero, de acuerdo a las sociedades donde los espacios públicos se han vaciado de la presencia de Dios o de toda referencia a una realidad última, pero donde aún existen las prácticas fervorosas de religión. Segundo, como sociedades donde las personas se han alejado de la Iglesia, cuestión que no necesariamente implica un desaparecimiento de la fe. Tercero, aquellas sociedades donde la fe es una de las tantas opciones humanas posibles (Taylor, 2007, pp. 21-23). Estando las tres formas relacionadas, es llamativo que en el tercer modo la fe sea asimilada como una alternativa más entre varias. Es una situación compleja para quienes profesan fe, porque siendo ella producto de la intelección y no mera cuestión del sentir (la fe tiene lugar en la experiencia vital de quien la sostiene), la fe debe ser justificada al igual que son justificadas las demás alternativas. Este aspecto incide fuertemente en la fragmentación institucional de la religión y también en la pérdida de las tradiciones originales, dando paso a la fuerza del racionalismo como único basamento del conocer. En síntesis, aumenta el desconocimiento de la realidad y la naturaleza humana.

Según lo sostenido hasta aquí, pensar que la modificación del mundo en términos del lugar de la religión en él se ha debido únicamente al efecto de la secularización es una afirmación parcial. Las ideas de lo secular no constituyen una teoría del ser y sus conceptos no consiguen edificar un sistema de explicación ontológica del hombre. La secularización, más bien, es un medio político pensado para poner en marcha el proyecto social moderno, hecho que puede relacionarse con la manera actual de entender la vinculación del hombre con lo divino o trascendente. Pero, la secularización por sí sola no podría producir un cambio ontológico en la naturaleza espiritual humana, como tampoco podría dar explicación antropológica acerca de la religión.

Como ejemplo de la imposible extinción de la religiosidad, el sociólogo luterano Peter Berger, ha expuesto que en la ciudad de Washington de Estados Unidos, son muchos los edificios religiosos que existen; católicos, protestantes, judíos, cristianos ortodoxos, budistas y un gran templo vietnamita comparten el espacio público (Berger, 2004, p. 65). Con ello, Berger no busca explicitar la ausencia de componentes antirreligiosos en la Ilustración estadounidense, sino mostrar que la secularización no ha tenido el efecto de extinguir universalmente la religión y sus prácticas. Todo ocultamiento de lo religioso no puede transmutar al ser humano en ser arreligioso. 


\section{CIERRe}

La permanencia del fenómeno religioso es por causa de una religación antropológica del hombre. Una religación que el ser humano ha mostrado dando forma, nombre y signo a deidades y fuerzas sobrenaturales. En otros términos, la religación es el modo connatural del ser humano fundado en lo fundante. Al afirmar Eliade que la realidad es estructuralmente una obra sagrada (Eliade, 2011, p. 11), también precisa que el hombre igualmente es una obra sacra. Por lo tanto, todo entendimiento que se busque acerca de la religión y sus múltiples formas, debe partir desde las bases de un estudio metafísico-antropológico-fenomenológico, no a través del enunciado de la secularización que es instrumento de un específico modelo socio-cultural-existencial.

Proyectar tan ampliamente la tesis de la secularización en lo referido al desencantamiento del mundo, significaría errar tanto en el juzgamiento de la realidad del homo religiosus, como en la aseveración sobre la extensión de la modernidad como causa del declive completo de la religión (Berger, 2016:9). Por otra parte, el abordaje de la secularización desde la filosofía de la religión, contribuye a aclarar la situación homo religiosus dentro de su historia secularizada; expresamente la secularidad social, debe advertirse como un momento dentro del proceso consciente ante la religiosidad.

En conclusión, las formas religiosas no son meramente las normas de obediencia moral; ante todo, las religiones han sido sistemas organizados del pensamiento humano. En este sentido, la reflexión que aborda hoy el retiro de las religiones $\mathrm{y}$, al mismo tiempo, el reconocimiento del pluralismo religioso ${ }^{12}$, debe contar con la categoría de la religiosidad como condición humana inherente. Ante esto, la fenomenología eliadeana ofrece tener en cuenta que la religión es una realidad que no solo trasciende las manifestaciones históricas, sino que ha generado la construcción de un mundo de significados (Duch, 2001:100) irrevocables para la sociedad.

\footnotetext{
${ }^{12}$ Peter Berger sostiene que es un error pensar que la secularización se favorece con el pluralismo religioso. Al mismo tiempo, Berger tiene a pensar que la coexistencia de distintas cosmovisiones y sistemas de valores en una misma sociedad, ha sido un cambio provocado por la modernidad respecto al lugar de la religión en la mentalidad de las personas y en el orden institucional; hecho que podría o no vincularse con la secularización. Pero, el argumento de la secularización es insostenible al momento de explicar la movilidad del hecho religioso. Además, los hechos muestran que el mundo es todo menos secular. Cf. Berger (2016). Los numerosos altares de la modernidad, Salamanca, Sígueme, 10.11.
} 


\section{BIBLIOGRAFÍA}

Alessí, A. (2004). Los caminos de lo sagrado. Introducción a la filosofía de la religión. Madrid: Ed. Cristiandad.

Berger, P. (2004). Las religiones en la era de la globalización. En: Iglesia Viva, nº 218, (pp. 63.72).

Berger, P. (2016). Los numerosos altares de la modernidad, Salamanca: Sígueme.

Duch, Ll. (2001). Antropología de la religión. Barcelona: Heder

Eliade, M. (1983). Imágenes y Símbolos. Madrid: Taurus

Eliade, M. (1996). Mito y Realidad, Colombia: Labor.

Eliade, M. (2000). La búsqueda. Historia y sentido de las religiones. Barcelona: Kairós.

Eliade, M. (2001). Nacimiento y Renacimiento. El significado de la iniciación en la cultura moderna. Barcelona: Kairós.

Eliade, M. (2011). Tratado de Historia de las Religiones, Madrid, Ediciones Cristiandad.

Eliade, M. (2015). Lo sagrado y lo profano, Barcelona: Paidós.

Farré, L. (1969). Filosofía de la religión. Buenos Aires: Losada.

Fraijó, M. (2005). Filosofía de la religión, Madrid: Trotta.

Habermas, J. (1986). Ciencia y técnica como «ideología». Madrid: Tecnos

Lucas, J. (1994). Dios, horizonte, hombre. Madrid: Biblioteca de autores cristianos.

Lucas, J. (1999). Fenomenología y Filosofía de la Religión, Madrid: Biblioteca de Autores Cristianos.

Luckmann, Th. (1973). La religión invisible. El problema de la religión en la sociedad moderna. Salamanca: Sígueme.

Luckmann, Th. (2008). "Reflexiones sobre Religión y Moralidad". En: Bericat Alastuey, E. (coord.), El fenómeno religioso. Presencia de la religión y de la religiosidad en las sociedades avanzadas, pp. 15,25. Sevilla: Centro de Estudios Andaluces.

Martín Velasco, J. (2002). El hombre y la religión, Madrid: PPC.

Pals, D. (2008). Ocho teorías sobre la religión, Barcelona: Herder.

Shaeffler. R. (2003), Filosofía de la religión, Salamanca: Sígueme.

Touraine, A. (2008). "Las relaciones entre religión y política en las sociedades contemporáneas". En: Bericat Alastuey, E. (coord.), El fenómeno religioso. Presencia de la religión y de la religiosidad en las sociedades avanzadas, pp.97-103. Sevilla: Centro de Estudios Andaluces. 